\title{
NIVELES PLASMÁTICOS Y FECALES DE ESTRADIOL EN YEGUAS DURANTE EL CICLO ESTRUAL Y LA GESTACIÓN TEMPRANA
}

\author{
Oscar Rodríguez B. ${ }^{1}$, César Novoa M. ${ }^{2}$, Víctor Leyva V. ${ }^{3}$ y Jorge Franco V. ${ }^{4}$
}

\section{Alstrict}

The correlation between fecal and serum levels of $17 \beta$ estradiol $\left(E_{2}\right)$ during the estrous cycle, follicular phase $\left(\mathrm{F}_{1}\right)$ luteal phase $\left(\mathrm{F}_{2}\right)$ and early pregnancy $\left(\mathrm{F}_{3}-\mathrm{F}_{6}\right)$ in mares was determined by radioimmuno assay (RIA) with the objective of developing a noninvasive method for monitoring equine reproduction. Ten Arabian mares from 4 to 10 years of age were divided into two groups determined by nursing status: $G_{1}$ with sucking foal, $\mathrm{n}=4$ and $\mathrm{G}_{2}$ non-nursing, $\mathrm{n}=6$. All were bred during their second heat with 6 resulting pregnancies. Blood and fecal samples were taken during the follicular phase (F1), luteal phase (F2), at $0-10$ days (F3), 12 to 16 days (F4), 18 to 36 days (F5) and 50 days (F6) of pregnancy. Hormone levels in blood $(10 \mathrm{ml})$ and fecal samples $(50 \mathrm{~g})$ were determined using Diagnostic Products Corporation (DPC) RIA test kits. In the fecal samples, the hormone was previously extracted by the Wasser technique. Hormone levels were 52.522 \pm 18.240 in the serum and $460.797 \pm 95.311$ in the feces, compared to $59.558 \pm 23.489$ (serum) and $338.431 \pm 69.737$ (feces) during gestation. The correlation coefficient, $\mathrm{r}=0.3411$ $(\mathrm{n}=500)$, was statistically significant $(\mathrm{P}<0.05)$, reflecting a relationship between serum and fecal hormone levels and indicating that detection of $17 \beta$ estradiol $E_{2}$ levels in the feces is a viable noninvasive technique for determining reproductive status in mares. Key words: Hormone, estradiol, serum, feces, mares.

\section{Resmmen}

Con el objeto de desarrollar un método no invasivo para monitorear el estado reproductivo en la yegua, se evaluó los cambios en niveles de $17 \beta$ estradiol $\left(E_{2}\right)$, durante las fases del ciclo estrual y los cincuenta primeros días de gestación. Se usaron diez yeguas entre 4 y 10 años de edad, del Centro de Reproducción Equina del Ejercito, Las Palmas, Barranco, Lima (altitud: $110 \mathrm{~m}$; latitud Sur: $12^{\circ} 05^{\prime}$; longitud Oeste: $77^{\circ} 02^{\prime} ; \mathrm{y}$ precipitación pluvial: 0.0 a $5.9 \mathrm{~mm}$ entre julio a diciembre, periodo en el que se realizó el estudio). Las yeguas fueron agrupadas en lactantes con cría al pie $(n=4)$ y $\sin$ cria $(n=6)$, y servidas en el segundo celo del ciclo estrual, resultando seis preñadas. Esto permitió evaluar fases del ciclo estrual al inicio en todas y luego, cambios en la gestación en las que quedaron preñadas $(n=6)$. Se tomaron muestras fecales y de suero sanguíneo, agrupándolas en: F1) Fase folicular, F2) Fase luteal y en las hembras preñadas, F3) 0 a 10 de preñez; F4) 12 a 16 d; F3) 18 a 36 d y F5) 38 a 50 d de preñez. En el caso de suero sanguineo se tomó $10 \mathrm{ml}$ de la vena yugular, en forma interdiaria entre las 11:00 y 13:00 horas; las muestras fecales fueron tomadas simultáneamente con las séricas, separándose $50 \mathrm{~g}$ para su desecación a $45^{\circ} \mathrm{C}$ y procesamiento y obtener $2.5 \mathrm{~g}$ de polvo fecal para su

\footnotetext{
'Centro de Reproducción Equina del Ejercito. Av. Las Palmas s/n - Surco

${ }^{2}$ Profesor Emérito - FMV - UNMSM

${ }^{3}$ Departamento de Producción Animal - FMV - UNMSM

- Instituto de Investigaciones de Altura UPCH
} 
determinación hormonal. La determinación de $\mathrm{E}_{2}$ en suero sanguíneo y heces se realizo mediante RIA de fase sólida usando kits comerciales del sistema DPC (Diagnostic Products Company CA, Los Angeles); se siguió el procedimiento descrito por Wasser. El análisis mostró una media de $52.522 \pm 18.240$ en muestras séricas y de $460.797 \pm 95.31$ en las heces durante el ciclo estrual y de $59.558 \pm 23.489$ y $338.431 \pm 69.737$ en heces durante la gestación, el coeficiente de correlación $r=0.3411(n=500)$ fue significativo $(p<0.05)$ indicando que existe correlación entre los niveles de $\mathrm{E}_{2}$ séricos y fecales sugiriendo que se puede utilizar heces como muestra para la determinación de los niveles de $\mathrm{E}_{2}$ en forma no invasiva en yeguas.

Palabras clave: Hormona, estradiol, suero, heces, yegua.

\section{wroumbitit}

En la explotación equina contar con medios no invasivos que faciliten el conocimiento del estado reproductivo de la yegua sería de gran utilidad para mejorar la eficiencia reproductiva; distinguir hembras preñadas de vacías y de éstas conocer si están ciclando y estimar la ocurrencia de ovulación, son algunos de los aspectos de interés práctico. El empleo de muestras de heces para medir niveles de estrógenos y a través de estos conocer el estado reproductivo de las yeguas, ofrece una alternativa que no requiere manipuleo excesivo de los animales.

Los estrógenos naturales endógenos y exógenos son conjugados en el hígado con el ácido sulfúrico o con el ácido flucorónico para luego ser excretados en la orina y las heces (Mc Donald, 1987; Shideler et al., 1993). Estudios durante la preñez en el gato doméstico (Brown et al., 1994) y en Macacus fascicularis (Shideler et al., 1993; Schwarzenberguer et al., 1996) demostraron que los estrógenos son excretados en las heces en un $40 \%$ como estradiol $17 B$ $\left(E_{2}\right)$ no conjugado y estrona y en un $60 \%$ como conjugados no hidrolizables. Con base en estos antecedentes, este estudio evalúa los cambios en niveles de $\mathrm{E}_{2}$ en heces de yeguas durante el ciclo estrual y durante los 50 primeros días de preñez y su utilidad como herramienta para monitorear el estado reproductivo de la yegua. Así mismo estudia su relación con los cambios de nivel en suero sanguíneo para desarrollar un método no invasivo en el monitoreo de la reproducción del equino.

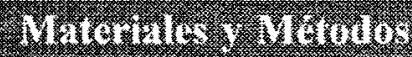

\section{Ubicación}

El estudio se realizó en el Centro de Reproducción Equina del Ejército, ubicado en las Palmas, distrito de Barranco, provincia de Lima, a una altitud de $110 \mathrm{msnm}, 12^{\circ} 05^{\prime}$ latitud sur, $77^{\circ} 02$ ' longitud oeste, la presión atmosférica mensual varió entre 998.1 a 1000.9 milibares, y una precipitación total mensual de 0.0 a $5.9 \mathrm{~mm}$ entre julio a diciembre, periodo en el que se llevó a cabo el experimento.

Las determinaciones hormonales se realizaron en el Instituto de Investigaciones de altura (IIA) de la Universidad Peruana Cayetano Heredia en la ciudad de Lima.

\section{Animales}

Se seleccionaron al azar un total de 10 yeguas vacías de raza árabe, de 4 a 10 años de edad, con un peso promedio de 440 $\mathrm{kg}$. Los animales fueron mantenidos con una alimentación en base a heno de alfalfa $y$ vainas de algarrobo, ración que fue repartida en 2 fracciones una a las 09:00 y otra a las 14:00 horas, con agua y sales minerales ad libitum. Durante la toma de muestras los animales permanecieron en cinco corrales de encierro, de acuerdo a su estado reproductivo.

Las 10 yeguas agrupadas en lactantes con cría al píe $(n=4)$ y sin cría $(n=6)$ fueron servidas en el segundo celo del ciclo estrual resultando 6 preñadas. 
Esto permitió evaluar las fases del ciclo estrual, al inicio en las 10 yeguas vacías y luego las fases de la gestación en las 6 yeguas que quedaron preñadas $(n=6)$.

\section{Muestras}

Para evaluar las fases del ciclo estrual se tomó muestras fecales y suero sanguíneo para determinar los niveles de estradiol durante la fase folicular (F1) y la fase luteal (F2). En las hembras preñadas también se muestreó heces y suero sanguíneo para determinaciones de estradiol. Este aspecto abarcó 4 periodos, el primero de 0 a 10 días (F3), el segundo de 12 a 16 días (F4), el tercero de 18 a 36 (F5) y el último de 38 a 50 días (F6) de preñez. En el caso de suero sanguíneo se tomó $10 \mathrm{ml}$ de sangre a cada animal por punción de la vena yugular en forma interdiaria entre las 11:00 y 13:00 horas, las muestras fueron centrifugadas a $2500 \mathrm{rpm}$ durante 5 minutos para la obtención del suero el cual fue conservado en congelación a $-20^{\circ} \mathrm{C}$ hasta su posterior determinación hormonal. Las muestras fecales fueron tomadas en forma simultánea con las muestras séricas, las que fueron homogenizadas tomándose $50 \mathrm{~g}$ para su desecación a $45^{\circ} \mathrm{C}$, luego triturada y tamizada en un tamiz $\mathrm{N}^{\circ} 100$ de malla de $149 \mathrm{mu}$ obteniéndose $2.5 \mathrm{~g}$ de polvo fecal que se guardó en viales a temperatura ambiente hasta su posterior determinación hormonal.

\section{Métodos}

La determinación de $\mathrm{E}_{2}$ tanto en suero sanguíneo como en heces se realizó mediante RIA de fase sólida utilizando kits comerciales del sistema DPC (Diagnostic Products Company CA, Los Angeles).

La sensibilidad del ensayo fue de 0.8 $\mathrm{pg} / \mathrm{ml}$. La extracción de las hormonas esteroides de las muestras fecales, antes de su determinación por RIA, fue realizada según lo especificado por Wasser et al. (1991) el protocolo es el siguiente: a $0.25 \mathrm{~g}$ de polvo fecal se le añadió $8 \mathrm{ml}$ de etanol química- mente puro y $2 \mathrm{ml}$ de acetona; se mezcló y dejó reposar por 30 minutos y se centrifugó a $2500 \mathrm{rpm}$ a $0{ }^{\circ} \mathrm{C}$ por 5 minutos. Luego el sobrenadante fue vertido en tubos de polietileno de $50 \mathrm{ml}$., al precipitado se le añadió $5 \mathrm{ml}$ de etanol, se mezcló y volvió a centrifugar y el sobrenadante obtenido se añadió al anterior, esta mezcla fue evaporada en una corriente de nitrógeno hasta alcanzar un volumen de $6 \mathrm{ml}$ al cual se adicionó $2 \mathrm{ml} \mathrm{de}$ agua destilada y se expuso nuevamente a la evaporación hasta obtener $2 \mathrm{ml}$ de solución, a la que se le agregó $2 \mathrm{ml}$ de dichlorometano y dejó reposar por 20 minutos. Pasado este tiempo se extrajo nuevamente el sobrenadante y sometió a evaporación con nitrógeno hasta su desecación total, al sedimento obtenido se le agregó $1 \mathrm{ml}$ de etanol y de ésta solución se tomó $20 \mathrm{ml}$ para ser procesado mediante RIA.

Sólo se utilizó 20 ul debido a que el protocolo RIA está calibrado para medir la concentración de un ml de solución utilizando 100 ul de muestra, como en la solución obtenida después del proceso de extracción de las hormonas esteroideas se encuentra el contenido de $\mathrm{E}_{2}$ equivalente a $5 \mathrm{~g}$ de muestra fresca se hace necesario tomar solamente la quinta parte de la cantidad requerida a fin de expresarlo en $\mathrm{pg} / \mathrm{g}$ de muestra fresca, ya que $0.25 \mathrm{~g}$ de polvo fecal equivale a $5 \mathrm{~g}$ de heces frescas.

\section{Análisis estadísticos}

El análisis de la información se hizo por mediciones repetidas utilizando el modelo mixto, considerando como efecto fijo a la unidad experimental (yeguas) que varió de $\mathrm{i}=1, \ldots, 10$ para la evaluación del ciclo estrual e $\mathrm{i}=1, \ldots, 6$ para evaluar la preñez. Las fases del estado fisiológico se las consideró como efecto aleatorio considerando para tal efecto todas las determinaciones realizadas durante cada fase, para la evaluación del ciclo estrual, $j=1, \ldots, 4$ considerando 2 fases para el grupo de yeguas con cría y 2 para el grupo de yeguas sin cría. Para la evaluación de la gestación $\mathrm{j}=1, \ldots, 12$, considerando 6 fases por 
cada grupo de yeguas en estudios ya que a las gestantes se las evaluó también considerando las fases del ciclo estrual en que quedaron preñadas. El modelo matemático lineal fue el siguiente:

$Y_{i j k}=u+a_{i}+b_{j}+\left(a_{i} b_{j}\right)+E_{i j k}$

Donde:

$\mathrm{Y}_{\mathrm{ijk}}=$ nivel de $\mathrm{E}_{2}$ sérico o fecal.

$\mathrm{u}=$ media poblacional

$a_{i}=$ Efecto fijo

$\mathrm{b}_{\mathrm{j}}=$. Efecto aleatorio

$\left(a_{j} b_{j}\right)=$ interacción yegua $x$ fase

$\mathrm{E}_{\mathrm{ijk}}=$ error experimental.

Para determinar el grado de asociación entre los niveles determinados en suero sanguíneo con los determinados en las heces se utilizó el análisis de correlación de Sperman; para determinar las diferencias entre medias se utilizó la prueba de Duncan.

\section{Resularios y Diseuvion}

Niveles de estradiol sérico y fecal en yeguas durante el ciclo estrual

Los resultados se presentan en el Cuadro 1. Podrá notarse que los niveles de $\mathrm{E}_{2}$ en la fase folicular fueron mayores que en la fase luteal $(\mathrm{P}<.05)$ tanto en las mediciones en suero sanguíneo como en las heces, $y$ en yeguas con cría y sin cría. Esto se debe a que en la fase folicular hay un incremento de la secreción de estrógenos debido al activo crecimiento de los folículos preovulatorios.

Se observa también que los niveles de $E_{2}$ fueron superiores en hembras con cría versus aquellas sin cría $(\mathrm{P}<0.05)$ tanto en las muestras sanguíneas como en las heces. Este hecho indica un efecto de la cría o de la gestación anterior sobre la concentración de $E_{2}$. Estudios en humanos informan un incremento del nivel de las proteínas transportadoras de hormonas esteroideas (SHBG) que se relacionan con el incremento de $\mathrm{E}_{2}$ durante la gestación (Mortimer, 1994). Probablemente en el equino el descenso del nivel de estas hormonas transportadoras sea lento resultando en un lento retorno de $\mathrm{E}_{2} \mathrm{a}$ sus niveles basales. También se observa que los valores de $\mathrm{E}_{2}$ medidos en las heces son notoriamente mayores que los valores medidos en suero sanguíneo en los dos grupos de yeguas evaluadas. En primates y otras especies se informa que las variaciones de $\mathrm{E}_{2}$ en las heces aún dentro del mismo animal podría deberse a una desigual distribución de la hormona (Wasser et al., 1991; Shideler et al., 1993; Heinsterman et al., 1993; Shideler et al., 1994 y Schwarzenberguer et al., 1996). Posiblemente se deba a que el anticuerpo usado en esta prueba esté determinando estrógenos totales y no solamente $\mathrm{E}_{2}$ (Shideler et al., 1994), aunque las especificaciones del fabricante le atribuyen una máxima especificidad para la detección de $\mathrm{E}_{2}$ y una mínima posibilidad de reacción cruzada.

Por otro lado, estudios realizados en humanos para determinár el índice de aclaramiento metabólico (MCR) determinaron que para $\mathrm{E}_{2}$ es de $1350 \mathrm{~L} /$ día y se realiza principalmente en el hígado, si tenemos en cuenta que el MCR es la cantidad total de sangre desde la cual es retirada una sustancia por unidad de tiempo (Mortimer 1994) y que el promedio de producción total resulta de multiplicar su concentración por el MCR se tiene la posibilidad de una producción total de $E_{2}$ equivalente a $81000 \mathrm{pg} /$ día, durante el inicio de la fase folicular, que se incrementaría hasta $945000 \mathrm{pg} / \mathrm{día}$ al término de la fase folicular y descendería a 270 $000 \mathrm{pg} /$ día durante la mitad de la fase luteal. Estos serían excretados mayormente en las heces, junto con la bilis (Becker, 1990; Mortimer, 1994). En base a ello, deducimos que la mayor concentración de $\mathrm{E}_{2}$ en las muestras fecales es el resultado del metabolismo durante un día, y que el suero sanguíneo sólo refleja la concentración de $1 \mathrm{ml}$ en un momento dado. 


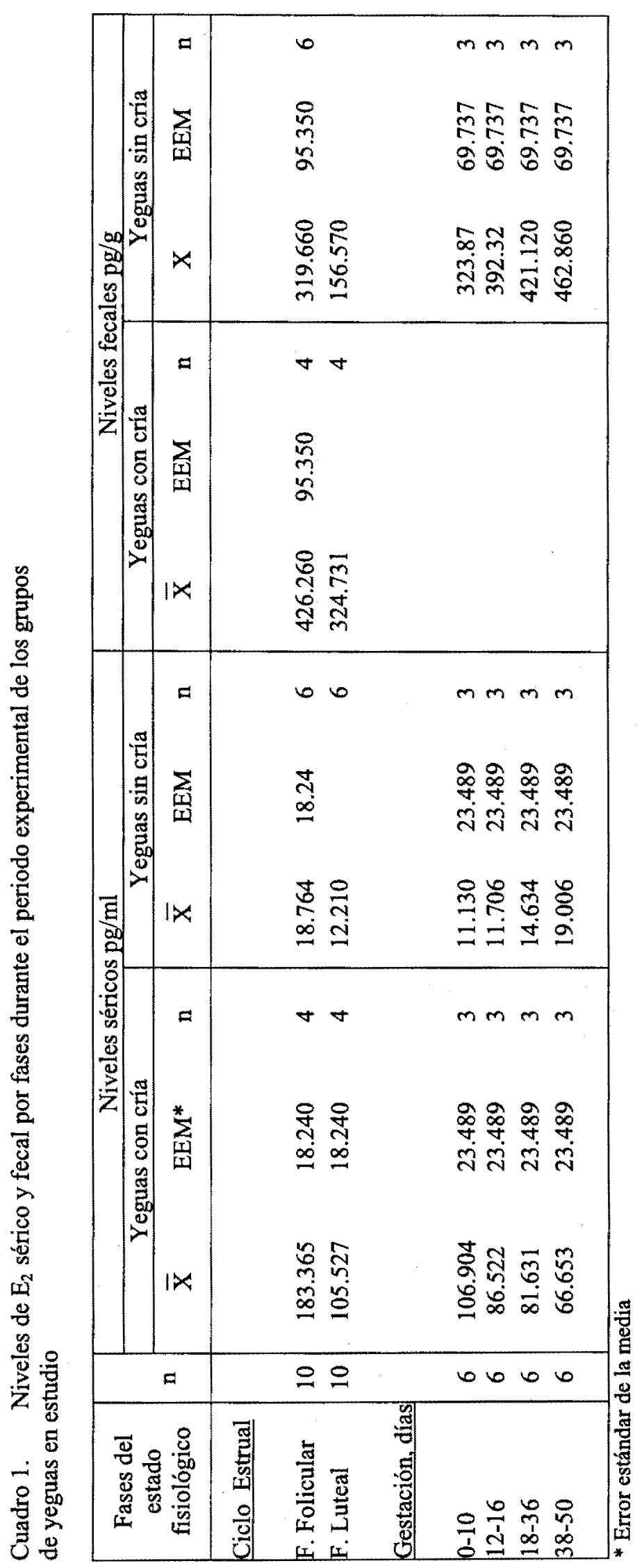


Niveles de $E_{2}$ sérico y fecal en yeguas durante los cincuenta primeros días de gestación.

Durante este período se observó tendencias diferentes del comportamiento del perfil sérico de $\mathrm{E}_{2}$ a medida que avanzó el proceso de gestación, dado que en el grupo de yeguas con cría fue descendente contrario a lo observado en el grupo de yeguas sin cría (Cuadro 1). La tendencia descendente del perfil sérico podría ser explicado por la disminución del MCR en el post parto, esto, se debería al incremento de la capacidad de unión del suero por un aumento del nivel de proteínas transportadoras, provocando disminución del MCR por la reducida extracción y metabolismo celular (Becker, 1990; Mortimer, 1994).

Durante la gestación se produce un incremento de las proteínas y albúminas transportadoras de $\mathrm{E}_{2}$ (Mortimer, 1994), por lo que es posible que estas proteínas se hayan mantenido durante el post parto y lentamente retornen a niveles basales. La reducción del MCR lleva a una disminución del promedio de producción, el cual es superado por la excreción y por lo tanto describe un perfil descendente en el suero sanguíneo y ascendente a nivel fecal para el caso del equino. En cambio, la tendencia ascendente del perfil sérico observado en el grupo de yeguas sin cría en pie puede ser debido a una mayor producción de $\mathrm{E}_{2}$ sujeta al desarrollo del blastocisto a medida que avanza el proceso de gestación, el mismo efecto se produce para el caso de heces (Gadsby et al., 1980).

En las yeguas gestantes al igual que durante el ciclo estrual, los valores determinados en las heces son notoriamente mayores a los valores medidos en suero sanguíneo (Cuadro 1), lo cual podría deberse a que el anticuerpo este determinando estrógenos totales, o a una desigual distribución de $\mathrm{E}_{2}$ en las heces y al MCR tal como se explicó para el caso del ciclo estrual.

\section{Correlación}

La relación entre los niveles séricos y fecales de $\mathrm{E}_{2}$ de las muestras tomadas el mismo día no mostró correlación significativa $(\mathrm{p}>0.05)$, sin embargo al relacionar el nivel de la muestra sanguínea con el nivel de la muestra fecal tomada 48 horas después, el coeficiente de correlación ( $\mathrm{r}=0.341)$ fue significativo $(p<0.05)$.

Esto sugiere que la fase de excreción de los metabolitos de $\mathrm{E}_{2}$ toma mayor tiempo que la fase de secreción y también podría estar relacionada con el tiempo de pasaje de las heces a través del tracto digestivo del animal (Shideler et al., 1994).

\section{Covolusturn}

1. Los niveles de $\mathrm{E}_{2}$ determinados a nivel fecal son mayores que los determinados en suero sanguíneo.

2. Hay un efecto del estado fisiológico (lactación y/o gestación anterior) sobre los niveles de $\mathrm{E}_{2}$ tanto en muestras séricas como fecales, dado que el grupo de yeguas con cría en pie mostraron niveles mayores que el grupo de yeguas sin cría en pie.

3. La significativa correlación $(r=0.3411)$ entre los niveles séricos y fecales de $\mathrm{E}_{2}$ de las yeguas indica que es factible utilizar heces como muestra para la valoración hormonal mediante RIA.

\section{Viteratura Gith}

1. Becker, L.K. 1990. Principles and Practice of Endocrinology and metabolism Fourth edition. Editorial JB. Lippincot Company Philadelphia. pp:142150.

2. Brown, J.L.; S.K. Wassery O.F. Wildt. 1994. Comparative aspects of steroid hormone metabolism and ovarian activ- 
ity in felids measured non invasively in feces. Biol. of Reprod. 51: 776-786.

3. Gadsby, J.E.; R. E. Heap y R.D. Burton. 1980. Oestrogen production by blastocyst and early embryonic tissue of various species. J. Reprod, Fert. 60:409417.

4. Heinsterman, M.; S. Tari y J.K. Hodges. 1993. Measurement of fecal steroids for monitoring ovarian function in new world primates callitrichidae. J. Reprod. Fert. 99: 243-251.

5. Mc Donald, L.E. 1987. Farmacología y terapéutica veterinaria. Edit. Acribia España. pp 609-619.

6. Mortimer, B.L. 1994. Steroid Hormones in Basic and Clinical Endocrinology. Edited by Greenspan FS, Baxter JD. Editorial Paramount Publishing USA pp 140-150.

7. Schwarzenberger, F; E. Mostl; R. Palme y E. Bamberg. 1996. Faecal steroid analysis for no invasive moni- toring of reproductive status in farm, wild and zoo animals. Anim. Reprod. Sci. 42:515-526.

8. Shideler, S.E.; A.M. Ortuño; F.M. Moran; E.A. Moorman y B.L. Lasley. 1993. Simple extraction and enzyme inmunoassays for estrogen and progesterone metabolites in the feces de Macacus fascicularis during non conceptive ovarian cycles. Biol of Reprod. 48: 1290-1292.

9. Shideler, S.E.; A. Savage; A.M. Ortuño; E.A. Moorman y B.L. Lasley. 1994. Monitoring female reproductive function by measurement of fecal estrogen and progesterone metabolites in the white faced saki. Anim. Jour. Of Prim 32: 95-108.

10. Wasser, S.K.; S.L. Monfort y D.E. Wild. 1991. Rapid extraction of faecal steroids by measuring the cyclicity and early pregnancy in free-ranging yellow babooms (Papio cynocephalus cynocephalus) Jour. Reprod. Fert. 92:415-423. 